\title{
Development of Merchantable Timber Volume Estimation of Pinus caribaea Plantations using Multi-Spectral Satellite Images
}

\author{
A. R. Gunawardena, S.P. Nissanka and N.D.K. Dayawansa
}

\begin{abstract}
The use of the multi- spectral remote sensing in relation to determination of parameters in the forestry is increasing globally. According to that, remote sensing is widely used to estimate above ground biomass, merchantable volume, carbon content and leaf area index in different vegetation systems.
\end{abstract}

Though there are many ways to estimate merchantable volume of plantation forest species, and filed inventory data is the most common. However, field inventory methods are more costly field consuming methods. Therefore, this study was initiated to develop merchantable volume prediction models using satellite image spectral response techniques for Pinus caribaea plantation at Mid-country wet zone of Sri Lanka.

P. caribaea is lightwood plantation species introduced to Sri Lanka and it was planted in marginal tea lands in mid and hill country. Initial site verification was done by ground truth GPS data with overlaying on unsupervised Landsat ETM+ image and demarcated the pine plantations at the Hantana region. Selected pine plantation was further classified into three different strata and six to nine plots were $(15 \mathrm{~m} \mathrm{x} 15 \mathrm{~m})$ established in each stratum to estimate volume. The total tree height $(\mathrm{m})$ and diameter at breast height $(\mathrm{DBH}$ in $\mathrm{cm})$ of individual trees inside the plot were taken and allometric equations (Forest Inventory Manual, 1996) were used to estimate merchantable volume in 23 plots.

Three vegetation indices Normalized Difference Vegetation Index was developed for research site using Landsat ETM+ satellite image and correlated with the estimated merchantable volume and develop linear regression model.

Results showed that the vegetation index of NDVI derived from satellite images is significantly correlated with calculated above-ground merchantable volume of P. caribaea. Finally, merchantable volume map was prepared for the P. caribaea plantation using the Satellite Image Processing and GIS based Software. The highest volume was observed in plot number $2\left(12.24 \mathrm{~m}^{3} / \mathrm{plot}\right)$ and the lowest $\left(4.972 \mathrm{~m}^{3} / \mathrm{plot}\right)$ and average volume is $400.646 \mathrm{~m}^{3} /$ ha.

Key words: multi -spectral, remote sensing, merchantable volume

\subsection{Introduction}

Sri Lanka is one of the countries having highest biological diversity in natural forests. However natural forest cover is drastically reduced in past few decades due to poor land use practices in agriculture, large scale agricultural land settlements, mega irrigation projects, encroachment, and illegal logging. Currently the natural forest cover is reduced up to 18 to $20 \%$. Continuous deforestation causes loss of biodiversity, global climate changes, habitat degradation and impact on hydrological cycle. Increas of Carbon dioxide $\left(\mathrm{CO}_{2}\right)$ and other green house gasses emissions, particularly those from fossil fuel burning and deforestation are increasingly causing global warming (NASA, 2001).

In the forestry practices, there is a need to estimate vegetation biomass, merchantable timber volume and basal area using forest inventory data. The traditional inventory of forest parameters based on fieldworks is often difficult, costly and time consuming to conduct in large areas. Remote sensing is one of the

A $R$ Gunawardena, Research and Special Project Unit Central Environmental Authority

S P Nissanka, Faculty of Agriculture, University of Peradeniya, Sri Lanka

ND KDayawansa, Faculty of Agriculture, University of Peradeniya, Sri Lanka 
feasible ways to acquire forest stand data at a reasonable cost with considerable accuracy. Advanced new remote sensing techniques such as, multi-sensor data fusion, increase spatial and spectral resolution and integration with Geographical Information Systems (GIS) make remotely sensed data, the primary source for many forestry applications. Extraction of forest stands parameters through correlation or regression analysis to examine relationship between spectral response and structural factors of forest such as timber volume, basal area, biomass, crown closer and vegetation density (Namayanga, 2002) in

This study was done on Pinus caribaea an exotic plantation species which was introduced by in early 1970s. P. caribaea is a medium-growing tree that reaches $45 \mathrm{~m}$ in height and more than 1 $\mathrm{m}$ Diameter of Breast Height (DBH) and the shafts are generally straight and free of branches. The bark is thick with wide fissures and is reddish brown to ashy brown. This variety has fascicles of three, and in the young trees these fascicles have four to six acicular leaves. The acicular leaves are 15 to $25 \mathrm{~cm}$ long and $1.5 \mathrm{~mm}$ wide; they are stiff and finely serrated, dark green to yellowish green, and covered with white stripes of stomata

The objective of this study was to identify the relationship between merchantable timber volume of Pinus caribaea with spectral responses of Landsat ETM+ satellite image and development of prediction volume maps.

\section{Literature Review}

Satellite driven models were developed by many scientists to estimate above ground biomass estimation which is related to this study for different vegetation types. Roy et el (1996) used Landsat TM derived model as NDVI, MIR to predict biomass content of natural forests in India and obtained $90 \%$ accuracy . Coops and Waring (2001), developed prediction of maximum annual above ground growth with derived forestry yield tables based on height - age relationship using satellite driven 3-PGS (physiological principles of predicting growth) model. Similar study was done on relationship between forest stand parameters and Landsat TM spectral response in the Brazilian Amazon forest (Dengsheng et al,
2004) and found the tree height is strongly affected to correlation with biomass and basal area distribution. Lue et al (2003) found the relationship between multi-angular satellite remote sensing (AVHRR and MODIS) and forest inventory data for carbon stock and sink capacity. Simplified process was developed to predict forest growth over diverse area of Eucalyptus forest using GIS implemented 3GP model with spatial layers by Tickel et al (2000).

\subsection{Methodology of Research}

\subsection{Data, materials and other information}

The primary data used in the study was Landsat ETM+ image acquired in 2001 and site verification was done using the 1: 50,000 scaled topographic maps and for demarcation of plots and geo-rectification of satellite images differential Global Positioning System (GPS) was used. P. caribaea plantation forest is located in the foothills of the Hantana mountain range which lies at an altitude between 1000 and $1500 \mathrm{~m}$ at mean sea level. Figure 1 shows the location of the research site.

Acquired satellite images were geometrically rectified into UTM

\subsection{Site stratification and Development of vegetation indices}

For site verification the selected Landsat ETM+ image was subjected to unsupervised classification to obtain 10 different classes and ground survey was conducted to collect GPS locations to identify different land cover types including pine, grassland, natural vegetation and settlements in research area. Differentialls

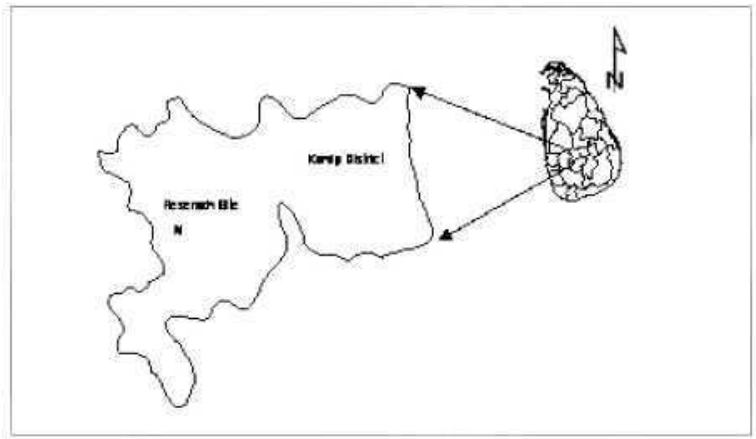

Figure 1. Location map of the study area (Universal Transverse Mercator) projection and datum WGS84 (zone 44) using ground control points obtained through GPS together with 1: 50,000 topographicmaps. 
corrected GPS locations were overlaid with unsupervised images. Using the ground truth information and visual interpretation representative, pine plantation area was extracted. To identify variability within the pine stratum same procedure of unsupervised classification was followed and pine plantation was stratified into 3 different strata

After the geometric rectification Landsat ETM+ was used to create Normalize Difference Vegetation Index (NDVI) map which is the most widely used index for biomass calculation and monitor vegetation (Panda, 2005).

Stratified random sampling technique was used to select sampling plots and size of the plot is 30 $\mathrm{x} 30 \mathrm{~m}$ and pre-defined to match one pixel satellite image. A total of 15 field sampling plots were used to obtain forest stand parameters and plots were demarcated using the differential GPS with sub meter accuracy.

\subsection{Data Collection and Checking}

\subsection{Variables measured in the field}

To estimate above ground woody biomass content and merchantable volume and derive satellite images the following information were collected in each plot. The field data collection was done in March 2006.

- Diameter at Breast Height (DBH):DBH tape was used to measure the diameter of the trees at the height of $1.3 \mathrm{~m}$ from the ground of the trees, which are above $10 \mathrm{~cm} \mathrm{DBH}$.

- Heights of the trees were taken using the clinometer and measuring tape.

- Canopy covem2/plot: Wide-angle digital photographs of the tree canopy were taken for each plot and canopy cover was calculated using computation.

\subsection{Measurement of merchantable timber volume}

The merchantable timber volume of pine trees were estimated through the field inventory data in the sample plots and above a minimum DBH $10 \mathrm{~cm}$ were measured. timber volume were estimated from DBH and combination of total height using locally relevant allometric equations developed by the forest department of Sri Lanka (1996).

\author{
Volume functions \\ $\mathrm{V}=0.0000187^{*} \mathrm{~d} 1.9606 * \mathrm{~h} 1.08939 *$ \\ $\left(1-83.86839^{*} \mathrm{~d}-3.04224\right)$ \\ $\mathrm{V}=$ stem volume in $\mathrm{m} 3$ to top diameter \\ $5 \mathrm{~cm}$ \\ $\mathrm{d}=$ diameter of breast height $(\mathrm{cm})$ \\ $\mathrm{h}=$ total height $(\mathrm{m})$ \\ (Forest Inventory Manual of Sri Lanka, 1996)
}

\subsection{Integration of field data with image spectral responses}

Sampled plots have accurate coordinates derived from high accuracy GPS device and were located on geometrically rectified, stratified Landsat ETM+ image during the field work. These plot data used to merchantable volume calculation and those values were linked with NDVI extracted from spectral response of satellite image (Landsat ETM+ 2001) to predict the total volume in the selected forest area and multiple regression analysis was done to find relationship between forest stand parameters and NDVI values. Finally, 8 new plots were placed in the site and obtained merchantable timber volume by field sampling techniques and compare with the Volume prediction map to check the accuracy of the derived model.

\section{SD:StandardDeviation}

\subsection{Results and Discussion}

\subsection{Pine plantation area identification and Delineation}

Unsupervised classification method was applied to the Landsat ETM+ image and developed 10 different classes to eliminate pixels with zero values and to gather similar pixels (Fig. 2). Collected ground truth locations of pine plantation perfectly fitted with class number 01 of unsupervised images and further verification was done by developing signature graph. The extracted classl layer of unsupervised 10 classes is shown in Figure 3 and its area is 198.96 ha. The spectral reflectance information of the pine layer is given in the table 1 . The selected layer converted to vector layer and it was used to delineation of Landsat TM image.

Using the algometric equation Forest (Forest Inventory Manual of Sri Lanka, 1996) parameter 
Table. 1. Spectral reflectance (digital numbers) of $P$. caribaea in ETM+ image

\begin{tabular}{|c|c|c|c|c|c|}
\hline \multirow{2}{*}{ Sensor } & \multirow{2}{*}{ ETM+ Band } & \multicolumn{3}{|c|}{ Spectral Reflectance Value (Digital Number) } \\
\cline { 2 - 5 } ETM+ Image & Minimum & Maximum & Mean & SD \\
& B1 & 62 & 86 & 72.338 & 4.543 \\
& B2 & 42 & 68 & 51.384 & 4.560 \\
& B3 & 29 & 71 & 41.402 & 6.078 \\
& B4 & 8 & 67 & 43.639 & 12.513 \\
& B5 & 1 & 56 & 33.380 & 10.154 \\
& B7 & 1 & 51 & 20.485 & 6.562 \\
\hline
\end{tabular}

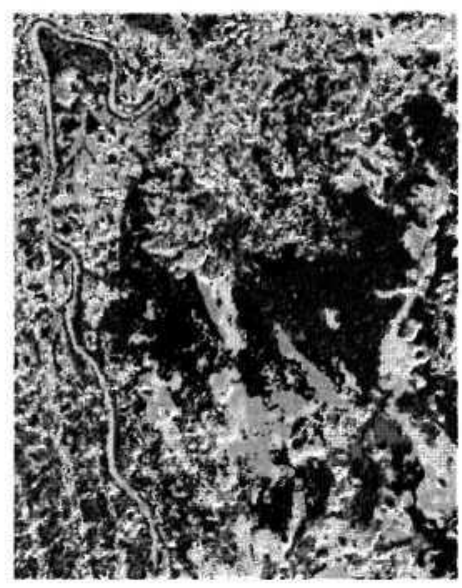

Fig. 2. Unsupervisedlo classes image (Coordinates: $07016^{\prime} 411^{\prime \prime} \mathrm{N}, 80035^{\prime} 27^{\prime \prime} E$ to $07013^{\prime} 25^{\prime \prime} \mathrm{N}$, $\left.80035^{\prime} 38.00^{\prime \prime} E\right)$

measurements and field derivative of estimations for each sampling plots are showing in Table 2. According to the results the highest estimated merchantable timber volume recorded was $11.49 \mathrm{~m}^{3}$ observed in plot number 11 lowest value $5.83 \mathrm{~m}^{3}$ and average volume is $400.646 \mathrm{~m}^{3} /$ ha.

Table: 2 Estimated merchantable volume and NDVI value of sampled plots

\begin{tabular}{|c|c|c|}
\hline Plot No & $\begin{array}{l}\text { NDVI } \\
\text { Value }\end{array}$ & $\begin{array}{c}\text { Merchantable } \\
\text { volume } \mathbf{~ m}^{3} / \text { plot }\end{array}$ \\
\hline $\mathbf{1}$ & 0.1398 & 9.70 \\
2 & 0.2083 & 11.24 \\
3 & 0.1489 & 9.04 \\
4 & 0.2391 & 11.49 \\
5 & 0.2308 & 10.05 \\
6 & 0.2000 & 9.62 \\
7 & 0.2211 & 10.06 \\
8 & 0.2174 & 9.94 \\
9 & 0.2043 & 9.18 \\
10 & 0.1011 & 8.18 \\
11 & 0.0652 & 5.83 \\
12 & 0.0714 & 6.34 \\
13 & 0.1220 & 7.97 \\
14 & 0.1059 & 9.05 \\
15 & 0.1778 & 7.95 \\
\hline
\end{tabular}

\subsection{Spectral reflectance and vegetation index values of sampled plots}

NDVI map was prepared and overlaid with respective plots (Figure 4). Spectral reflectance and vegetation index values of each plot is show in Table 5. The highest NDVI value was recorded in plot $4(0.2391)$ white the lowest in plot 11 is 0.065 . The highest NDVI values were observed in high dense vegetation due to higher leaf area index (Jensen, 2004). Gong and Miller (1995) evaluated number of spectral indices for boreal forests and concluded that NDVI was a best correlated index with LAI.

\subsection{Relationship between Volume and NDVI}

According to the results NDVI is significantly correlated $\mathrm{Y}=22.52 \mathrm{x}+5.359(\mathrm{r} 2=0.715)$ with total estimated merchantable wood volume of $\mathrm{P}$. caribaea (Figure 5). Derived linear regression equations was applied for NDVI image of

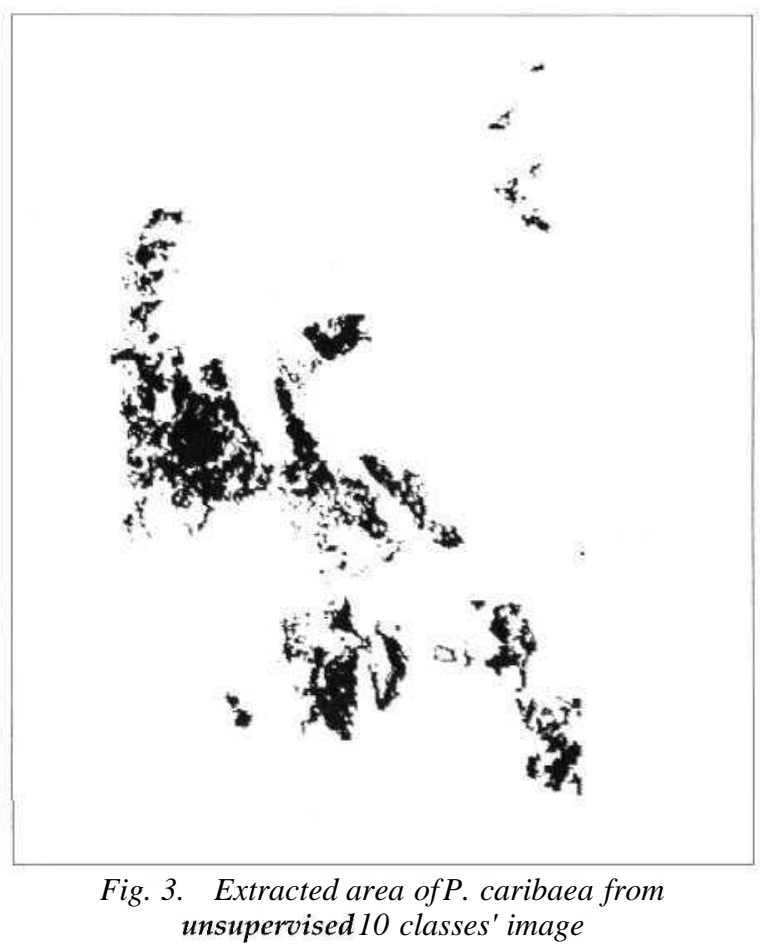




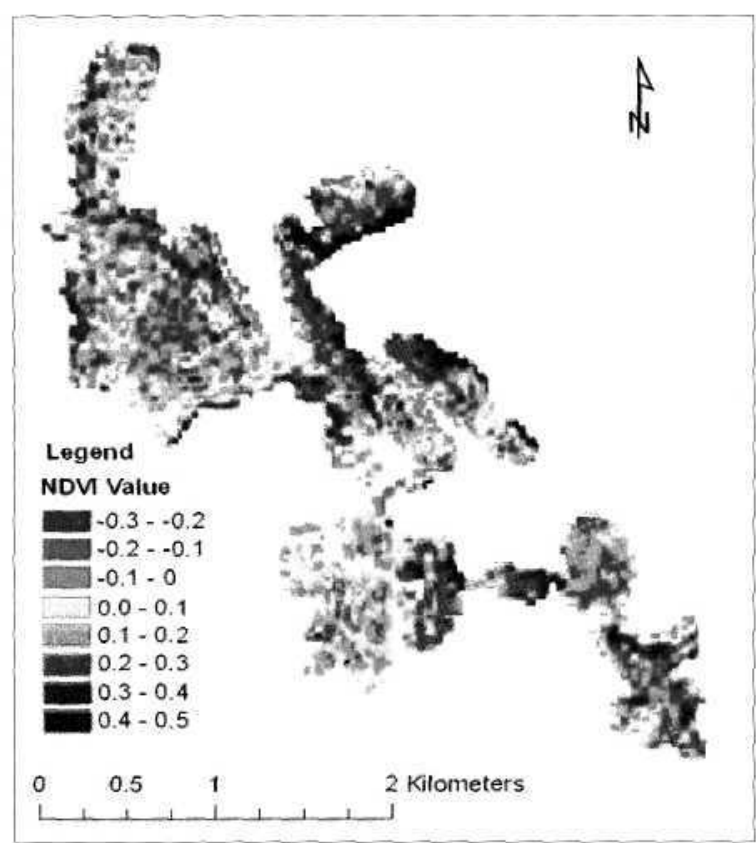

Fig. 4. NDVImap of P. caribaea Plantation at Lower Hantana region derivedfrom Landsat TM+ image

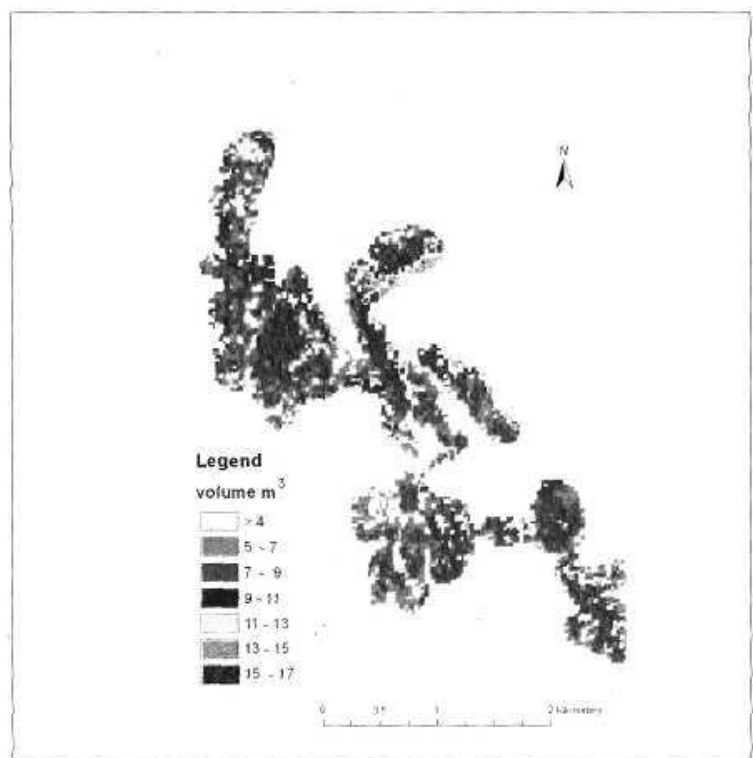

Fig. 5. Relationship between estimated tree volume of plot and NDVI

Landsat ETM+ 2001 and found the total merchantable volume of whole pine plantation using satellite image analysis and GIS based software.

\subsection{Accuracy assessment}

There were 8 field sampling plots which were placed randomly in the same study area to assess the accuracy. From each plot DBH, total tree height and GPS location were taken. Using forest stand data total, the above ground biomass and timber volume in each plot were

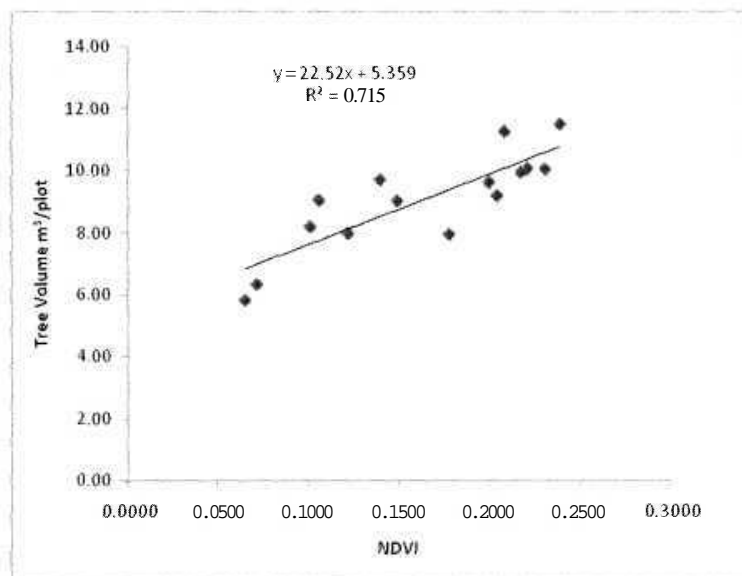

Fig.6. Estimated merchantable volumes of $P$. caribaea plantation in year 2001 (Gunawardena et al, 2008)

calculated and compared with the estimated values which were previously derived model using NDVI. According to the results, is shown the little over estimation (9.34\%) occurred in calculation of timber volume using derived model have an acceptable mean accuracy is $90.659 \%$.

\subsection{Conclusions}

NDVI from Landsat ETM + is significantly correlated with the merchantable timber volume of $\mathrm{P}$. caribaea in study area with $\mathrm{Y}=22.52 \mathrm{x}+$ $5.359(\mathrm{r} 2=0.715)$ model. However, these predicted timber volumes are applicable for pine with age classes of 20 to 30 years growing in Mid-country wet zone region of Sri Lanka. Presence of canopy cover is one of the critical factors which affected the prediction of timber volume through vegetation indices. However there are many factors which will affect on error propagation of estimating timber volume such as Leaf Area Index, under growth vegetation, atmospheric scattering, soil moisture, slope and sun angel.

\subsection{References}

1.0 Coops N.C, and Waring R.H, (2001), Estimation forest productivity in the eastern Siskiyou Mountains of Southwestern Oregon using a satellite driven process model, 3-PGS. NRC Research Press website.

2.0 Densheng, Lu., Mausel, P., Brondizio, E. and Moran, E. (2004). Relationship between forest stand parameters and Landsat TM spectral response in the Brazilian Amazon Basin. Forest Ecology and Management:157. 
3.0 Gong; P., Pu, R., Miller, J.R. (1995). Coniferous forest leaf area index estimation along the Oregon transact using compact airborne spectrographic imager data. Photogram Eng. Rem. Sens. 61: 1107 - 1117.

4.0 Gunawardena J.A.R, Nissanka S.P., and Dayawansa D., (2008), Change Detection of Merchantable Timber Volume and Above Ground Woody Biomass of Pinus caribaea plantations using multi-dates Satellite Imagery. Proceeding of 5th National Symposium on GeoInfomatics.

5.0 Jensen, J.R. (2004). Remote sensing of the environment, an earth resource perspective. Pearson Education (Singapore) Pte Ltd: 333 - 378 Khadka, M., 2005.

6.0 Liu.X, Fafators, Gomez.R.B and Wolf.H, Multiangular satellite remote sensing and forest inventory data for carbon stock and sink capacity in the Eastern United States forest ecosystems (2003)

7.0 Ministry of Environment and Natural resources. (1996). Forest Inventory Manual of Sri Lanka,

8.0 Namayanga, L.N. (2002). Estimating terrestrial carbon sequestered in above ground woody biomass from remotely sensed data. International
Institute for Geo-information Science and Earth Observation, Netherlands: 10 - 12.

9.0 NASA. (2001). NASA Facts Sheets [Online]. Available by NASA http://pao.gsfc.nasa.gov/ gsfc/service/gallery/fact_sheets/earthsci/ warming.htm

10.0Panda, B.C. (2005). Remote sensing principles and applications. Viva books Privet Limited, New Delhi. 100 - 148.

11.ORoy.P.S., and Shirish A Ravan, (1996), Biomass estimation using satellite remote sensing data an investigation on possible approached for natural forest. Journal of biosci., Vol.21, pp 535-561.

12.0 Tickel .P.K., Coops N.C., Hanfer .S.D., The Bogo Science Team, (2000). Assessing forest productivity at local scale across a native eucalypt forest a process model, 3PG_SPATIAL. Forest ecology and management 152 (2001) pp. $275-291$.

13.0Wood density database, 2001. (www.worldagroforestrycentre.org / sea / Products / AFDbases/ WD/asps/ DisplayDetail.asp/SpecID=2666) 